\title{
The New Experience for Business: Why User Experience Is the Differentiation Strategy in the Cloud Context
}

\author{
Andrey Sirotkin and Bronan McCabe \\ VTT Technical Research Centre, \\ Kaitoväylä 1, P.O. Box 1100, Oulu, FI-90571, Finland \\ \{andrey.sirotkin, bronan.mccabe\} @vtt.fi
}

\begin{abstract}
Could technologies transform software industry and drive the salience of user experience as differentiation strategy. However the current product augmentation paradigm conditions company's ability to design and market an experience product. Without new perspective on product augmentation a company may not succeed in communicating the value of user experience to its customers. Thus the differentiation strategy may be jeopardized. The paper proposes the transformation of traditional view of augmentation. The new model reflects the need for designing user experience prior to product or service development. Companies must build new capabilities to build a successful user experience differentiation strategy.
\end{abstract}

Keywords: user experience, differentiation, product augmentation, cloud computing.

\section{Introduction}

Despite many challenges for advancement of Cloud technologies [3, 5], Cloud computing shapes the way software is developed and marketed [7, 16]. The developers do not need large capital resources to implement innovative ideas. Scalability of cloud services eliminates the risk of in-house over- or under-capacity of computational power, thus minimizing the threat of overinvestment in hardware or lost of potential revenue. Furthermore, the cost structure changes as software becomes a service rather than an application sold for an isolated environment. Pricing models become a key element for reaching vast markets with economies of scale allowing to set zero or close-to-zero prices [1]. As service-based software undergoes standardization to support reuse of elements in different environments and scalability of services [2] it furthers the commoditization of software products.

As a result, the barriers of competition in software industry change. Innovative ideas can find their way to market utilizing Cloud resource. It is a growing challenge to be differentiated from growing competition. In Cloud context value of product or service as perceived by customer becomes a key differentiating factor. This draws interest to user experience as a differentiation strategy because it can provide an opportunity to add value to customers. That said, communicating the added value is a challenge primarily because, if it is not distinguished from aesthetics and usability then customers are unlikely to perceive it as differentiating and of consequence, are unlikely to be attracted or pay anymore for it. 
A software company which seeks to differentiate its products or services must recognize that it cannot achieve the desired results by simply adding more services to an existing product. A differentiating experience is created in the way a product or service is conceived [6] and marketed. For many software companies this means that should they wish to transition into the experience market [11] they will need to consider new capabilities for supporting it. Whilst aesthetics and usability design is important, on its own it is likely to be insufficient in the new business arena of experience. Failing to recognize the gap between current design processes and those required for developing experience will likely result in doing-more-of-the-same, and failure to differentiate.

\section{Experience Enabled by Cloud}

By definition experience is personal and unique, meaning the ability to stage a unique and memorable event is fundamental for experience creation [11]. This is flexibility of a different kind and it hinges on competence development, i.e. providing enough flexibility in organizational processes to enable consumption by an audience of one. However, organizations are driven by the production of goods and services that are created for mass consumption. This tension is creating a paradigm shift; one in which organizations have to balance the need for mass production with the consumers desire for personalization [13].

A distinct characteristic of the user experience business is the opportunity for the users to create their own experience. The product which a customer gets is the experience that he or she creates in partnership with the company. It is different from customization or user-centered design, which employs methods for producing a final product targeted at satisfying known consumer needs. An experience product is a result of value co-creation and is targeted at satisfying customer values.

Human values are known to be universal [14] but they are understood, expressed and attended to differently depending on context and situation [17]. Thus understanding customer values, contextualizing them and designing an experience targeting values all become a pivotal principal of success.

Creating and delivering experience offerings requires advanced understanding of criteria individuals use to evaluate experiences against their standards and preferences. Cloud technology makes such comprehension possible. This means that companies that operate in cloud business are well positioned to take advantage of the experience business. Cloud business benefits from access to a wide range of consumers, on the one hand; and an ability to accrue a deep sense of customer desire at an individual level on the other. Thus Cloud can be one of the means for a company to utilize its resource base to deliver a unique experience for every customer as suggested by Prahalad and Krishnan [13]. In other words, cloud technology makes tailoring experiences for one customer possible.

Although tourism, entertainment and other service businesses have been long exploring the idea of an experience offering, the cloud phenomenon opens up the experience market for the producers of all kinds of goods and services. Cloud companies can appeal to customer values on a personal level, with great accuracy. Corporate management can leverage new internet-based technologies to align internal system architecture with the life events of individual customers and thereby opening up new prosperous business opportunities. 


\section{Research Focus and Methods}

Experience design is subject to much debate in business and academic communities (e.g. [8]). This paper used case-base research approach to understand the issues underlying a company's weakness in differentiating its experience products from other software products. The goal of the study was to suggest ways to enhance the competitiveness of the user experience business in the context of Cloud. Case-based research can be very effective when reviewing challenges in the existing environment [18].

The paper is based on a study of a Finnish business unit in a multinational company. It included interviews of middle management in the unit. Soft system methodology [4] was utilized in structuring and analyzing the interviews. Additionally freely available information from web-sites and publications was used for culture web analysis [9] and core competence model [12]. The findings initiated the review of the current product augmentation paradigm [10]. Since case-based research can be used to initiate the development of a theory [8], this paper shows how the current product augmentation view must be modified in order to reflect the process of designing an experience offering.

\subsection{Data Collection and Analysis Methods}

The interviews consisted of two parts and a total of five managers were interviewed. During the first part each interviewee was asked to draw elements relationships and conflicts of user experience rich picture. Later all pictures were combined into a common view. This approach was selected for two reasons. First, it gives an opportunity to build a holistic perception of user experience while avoiding extensive debate over specific terms. Second, it unites employees with different backgrounds and combines their diverse views around one shared view. The other half was a semistructured interview regarding the company's perceived strengths and weaknesses.

Soft system methodology [4] was used to establish the current and desired views of user experience. Root definitions for both views were developed with the help of CATWOE method [4]. The comparison of the currently perceived and future company positions identified gaps and generated suggestions about possible changes. Prahalad and Krishnan [13] suggest that such analysis is necessary for building new corporate capabilities. The current business situation was described by the following definition.

A system owned by the company and carried out by its experts via the software development process - produces unsatisfied customers because the company's worldview is technology expertise and is constrained by the understanding of end users.

The same method was used to develop a definition of the desired future.

A system owned by the company and targeted at user experiences creates happy customers because it utilizes understanding of end customer values where experience is the worldview.

By comparing the elements of the two definitions the company can plan steps for creating capabilities for desired future [13]. For example, the company must alter its transformation process in order to produce satisfied customers. However the worldview conditions the changes that could be made in the transformation process. The new world view has to be grounded in understanding what customers value in software experience. This understanding is expressed in the way management thinks 
about the experience business. Thus transforming the way the company thinks about its business would facilitate the desired change.

Culture web analysis and core competence model were used to refine the understanding of the perceived situation and the depth of required modifications. The product augmentation model [10] was used to summarize the change that the company has to make in order to build capabilities for experience market.

The overarching theme of the findings was that the company is in the business of developing software rather than designing experience. User experience is perceived as designing the "look and feel" and is not aimed at customer values. Development of software for corporate partners needs to include more of the end user perspective on the product. This is because corporate partners do not value technology per se but rather view it as means for satisfying end user needs. For the company to develop a user experience competence it must serve its B2B partners with awareness of end user values [13]. That is, the company has to understand what kind of experience it wants to provide to end users.

Findings of the research were presented and discussed with the management. As a result some immediate changes were made to the development process with a greater focus on end users. The midterm goals were set for improving the multidisciplinary team competence. Also a more extensive follow-up study of user values in the Cloud context is planed. In the long term the company plans to incorporate the understanding of end user values in the design process. This will help the company to continue its transition from the software developer to an experience designer.

The generalized principles of designing experience are discussed in the following section.

\section{Designing Experience}

The case study proposed a broad assumption that there are two generally held perspectives on user experience. The first one focuses on customers' goals, needs, behaviors, and emotions when using a product (e.g. [15]). A company surveys various market segments and incorporates the feedback to improve its products. This is a traditional approach that perceives user experience as an incremental product improvement. The challenge with this view is that experience is only perceived at a product level.

As it was discussed above Cloud technologies shift perceive customer value from tangible product towards an intangible experience. The case-study company was being affected by such an external force. A failure to recognize the changes initiated by Could may lead to overlooking the new opportunities and instead being threatened by industry drivers.

The company in our research may be representative of some interactive technology producers who adopt the above view of user experience. Such a company may choose to evaluate user experience by measuring how an offering fulfils customers' needs and wants. This perspective gives the ground for setting new targets and measuring the magnitude of user experience. As a result a product is being gradually improved as more observations of the product usage are collected. However such an approach is questionable. Henry Ford is known for saying, "If I'd asked my customers what they wanted, they would have said faster horses." Hence a company that aims at satisfying 
only known expectations is unlikely to become a key influencer in a market. Moreover, in waiting for feedback the company risks always being one step behind the industry innovators. Market studies are still important; however, their interpretation should be adjusted to take into account that customers may not know any better ways of satisfying their needs than in the current context. Additionally, they may not suggest methods for altering the context, either.

The companies that put a product in the center of their design process view user experience as an incremental improvement of the existing product. Figure 1 illustrates the conventional business view of product augmentation [10]. At the core, the product appeals to a known need and the actual product is designed to satisfy it. Services are then added to the actual product to provide some level of differentiation. User experience is viewed as adding another augmentation layer for achieving more differentiation. Corporate management treats experience product in much the same way as it does the other layers.

The challenge with this approach is that current business processes may fall short of designing for fun, enjoyment or pleasure. The problem is compounded when trying to add other experience qualities such as hedonics. Though such qualities are not inherent of a product, they are attributed to it during the experience of it. Because actual and augmented layers are both a part of user experience, all blur together in the minds of both designers and customers. Thus, it becomes very difficult to communicate any added value proposition.

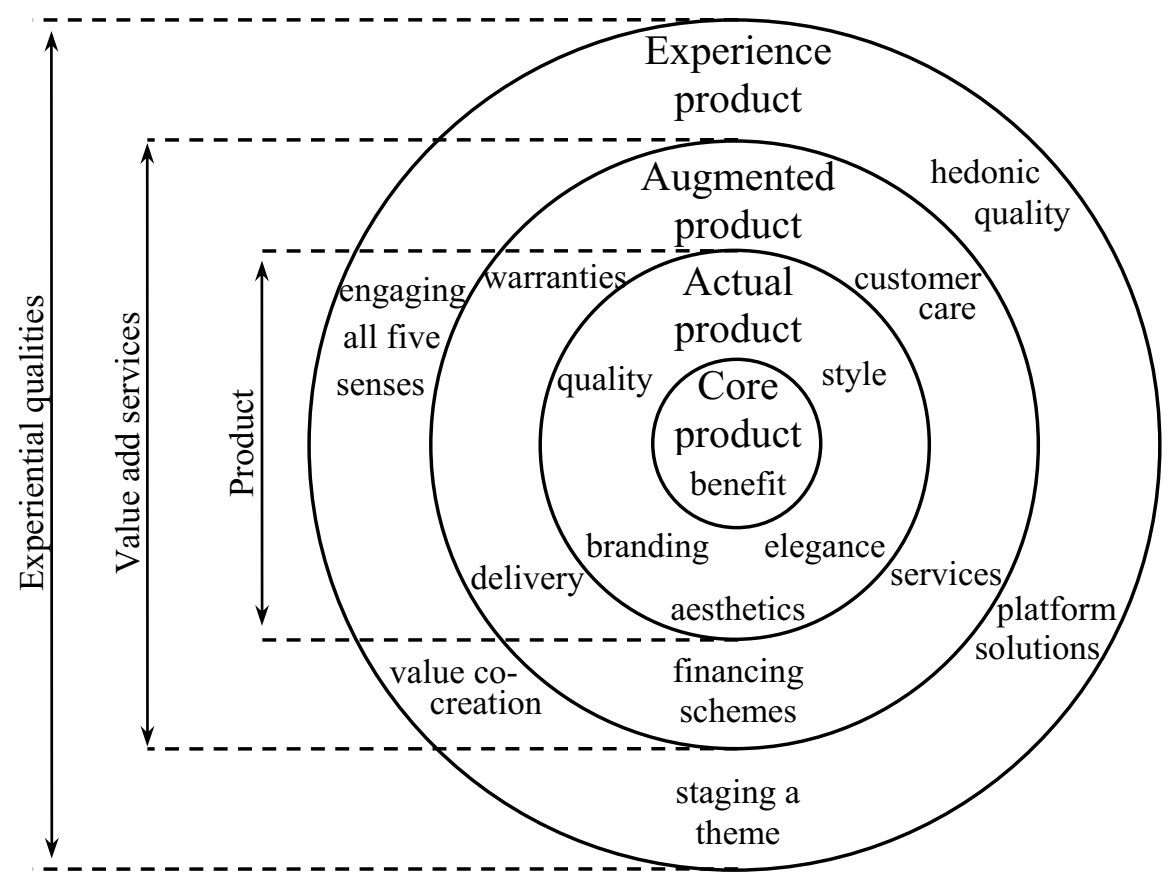

Fig. 1. Conventional business view of product augmentation 
There is a noticeable difference between an organization that sells actual products and its competitor who provides augmentation, i.e. customer support and a warranty in its offering. The two companies compete at a different level, enabling one to differentiate itself from the other. However, in order to provide this differentiation and move from an actual to augmented product offering, an organization must develop certain corporate capabilities. This is similar to the transition an organization must make to provide an experience offering.

The second perspective and a different view of user experience is when an organization emphasizes the competencies that enable design for experience in the first place [6]. In other words, corporate management aims at certain kind of experience and designs an offering that supports it. This perspective creates a need for business change, which begins with the transformation of the company's viewpoint and focuses on the development of capabilities. The challenge is to combine diverse resources and deliver personalized experiences in all business areas that a customer comes in contact with.

The experience business model differs from the traditional one. It is grounded in the principle of staging an experience [11]. A companies' production process brings together talents, resources, goods and services in a coherent whole that engages individual customers. Consumption becomes a co-creation of experience, in which both customers and a company are involved [13]. The resulting take-away product is a memorable event. This is a competition imperative. This means that corporate management should view all the company's outputs, processes and resources as means for making a platform where customers can create their personal experiences in partnership with the organization. In designing experiences there is a great need for this new mindset. Re-evaluation of the business viewpoint and re-alignment of the capabilities and strategies are the prerequisites of offering user experience as a product.

The focus of design shifts from an attempt to make a hedonic product to staging an experience. The goal of market research also moves from surveying needs to understanding the value of experiences also. When values are contextualized they can be expressed as needs. Knowledge of values enables a company to shape the context around them and empower the customers to have their diverse needs met as they engage with a product on a personal level.

Contrary to the conventional product development view the step that follows value analysis is not actual product but experience design. Since needs are subjective and context dependent it is sensible to understand how the company will shape the experience. Therefore, any organizational offering should start with answering the question, "what kind of experience should this product or service be designed to deliver". Experience becomes a central concern and the product is designed around it. The value of the product is attributed to it by the customer either during an experience or a series of experiences. It is an attribution process that makes the product highly valuable to the customer. 


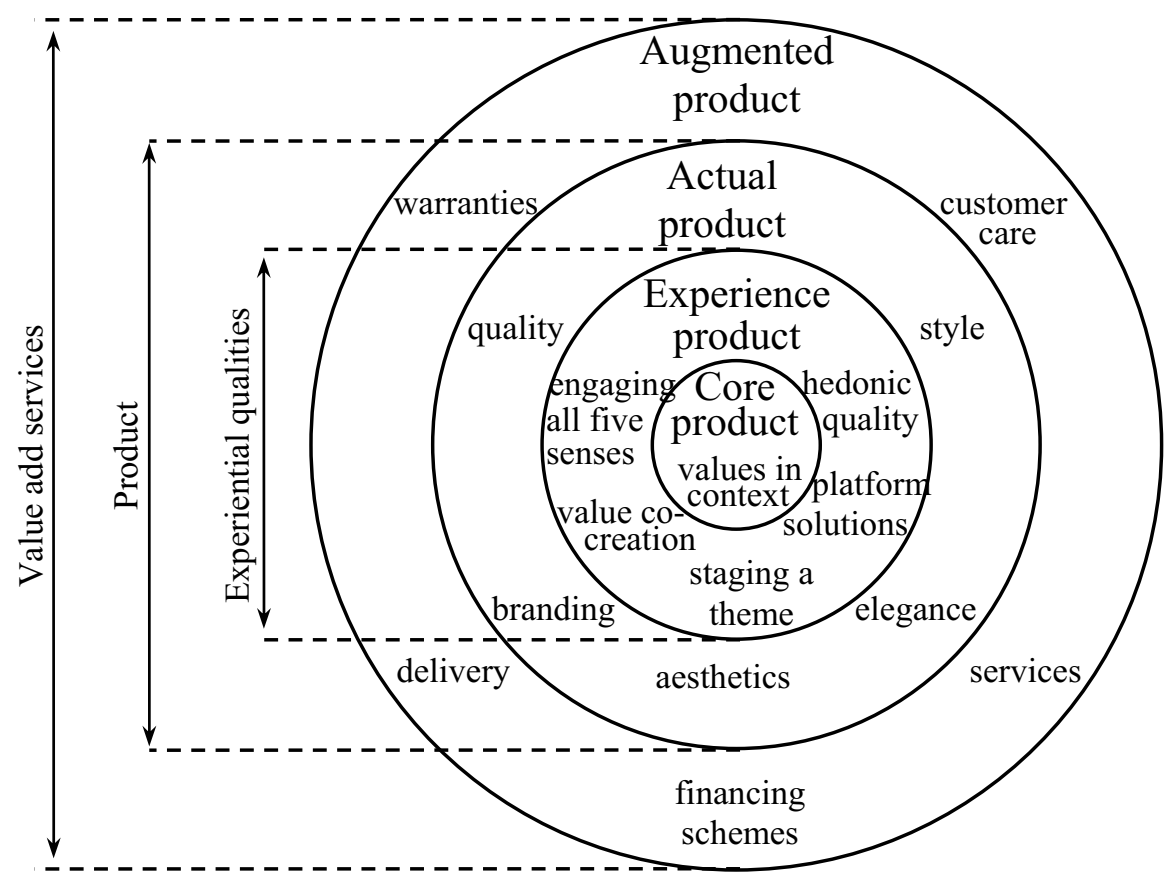

Fig. 2. Paradigm shift for experience product

As a result of the changed business viewpoint an organization makes not product, but experience central to its development process. Figure 2 summarizes the paradigm shift of product augmentation. Experience becomes central to the design offering with actual product and additional services supporting the experience design. The value is cocreated by customers as they use a product in various situations. The support for such a perspective requires an organization to develop a strategy for investing in corporate capabilities. These new capabilities support the transition to the next level of differentiation, which is an essential ingredient for gaining competitive advantage.

\section{Conclusion}

While the user experience business may seem like an incremental step for software integrators it is important to recognize the extent of change required to embrace the opportunity. Based on the perception of the current situation in the case study an experience that a good software developer provides may not be the one its customers value. Thus it can be questioned whether the company is truly designing experience. It may be that there is some confusion between designing experience and elegance. As a result a company's ability to take advantage of the experience market is at best limited. However, if a clear distinction between experience offering and usability or 
aesthetics is made (i.e. the desired and current states), a company has the ability to produce sustainable added benefits and communicate them well.

Conventionally organizations focus their efforts on actual product design. At VTT, we suggest that the foremost task is to focus on the experience for which the product is being designed. This can be achieved by studying customer values and contextualizing them for a particular market or context. Cloud technologies can enable companies to accrue knowledge about experiences that their customers value. Understanding the experience allows the company to develop a strategy for building user experience competence. In the Cloud business landscape user experience provides the differentiation that enables companies to compete, tolerate uncertainty and gain competitive advantage.

\section{References}

1. Anderson, C.: Free: The Future of a Radical Price. Random House Business Books, London (2007)

2. Buyya, R., Yeo, C.S., Venugopal, S., Broberg, J., Brandic, I.: Cloud Computing and Emerging It Platforms: Vision, Hype, and Reality for Delivering Computing as the 5th Utility. Future Generation Computer Systems 25(6), 599-616 (2009)

3. Carr, N.: The bid switch: Rewriting the World, Edison to Google. Norton, New York

4. Checkland, P.: Systems Thinking, Systems Practice. John Wiley \& Sons, Chichester (2009)

5. Dikaiakos, M.D., Katsaros, D., Mehra, P., Pallis, G., Vakali, A.: Cloud Computing: Distributed Internet Computing for IT and Scientific Research. IEEE Internet Computing 13(3), 10-13 (2009)

6. Eisenhardt, K.M.: Building Theories from Case Study Research. The Academy of Management Review 14(4), 532-550 (1989)

7. Hassenzahl, M.: Technology for All the Right Reasons. Morgan \& Claypool, San Rafael (2010)

8. Hassenzahl, M., Tractinsky, N.: User Experience - a Research Agenda. Behaviour \& Information Technology 25(2), 91-97 (2006)

9. Johnson, G., Scholes, K., Whittington, R.: Exploring Corporate Strategy, 8th edn. Person Education, London (2008)

10. Kotler, P.: Marketing Management. 11th international edn. Person Education, Upper Saddle River (2003)

11. Pine II, B.J., Gilmore, J.H.: Welcome to the Experience Economy. Harvard Business Review 76(4), 97-105 (1998)

12. Prahalad, C.K., Hamel, G.: The Core Competence of the Corporation. Harvard Business Review 68(3), 79-91 (1990)

13. Prahalad, C.K., Krishnan, M.S.: The New Age of Innovation: Driving Co-created Value through Global Networks. McGraw-Hill, New York (2008)

14. Schwartz, S.H.: Universals in the Content and Structure of Values: Theoretical Advances and Empirical Tests in 20 Countries. Advances in Experimental Social Psychology 25, 1 65 (1992) 
15. Tullis, T., Albert, B.: Measuring the User Experience: Collecting, Analyzing, and Presenting Usability Metrics. Morgan Kaufman, Burlington (2008)

16. Vouk, M.A.: Cloud Computing - Issues, Research and Implementations. In: Information Technology Interfaces, ITI 2008, 30th International Conference on Information Technology Interfaces (2008)

17. Williams Jr., R.M.: Change and Stability in Values and Value Systems: a Sociological Perspective. In: Rokeach, M.: Understanding Human Values: Individual and Societal, pp.15-46. The Free Press, New York (1979)

18. Yin, R.K.: Case Study Research: Design and Methods, 4th edn. Sage, Los Angeles (2009) 